\section{Safe transferring of intensified insulin therapy}

\section{Dear Sir,}

Diabetes education is generally considered to be a simple and cheap part of diabetes care or just a real "key" for a dramatic improvement of the patients' condition [1]. This opinion could be particularly important for the Eastern countries. The Romanian Diabetes Society was the first Eastern organizer in 1982 of a Workshop on Diabetes Education (under the auspices of Diabetes Education Study Group). At that time, in cooperation with a team from Dusseldorf, we completed the so-called "Bucharest-Dusseldorf Study" and demonstrated the possibility of transferring a structured teaching and treatment programme from a diabetes centre with a high economic level to another with a lower economic level [2]. Under experimental conditions and by strict metabolic control, based on daily blood glucose monitoring, an impressive reduction in the incidence of ketoacidosis and hospitalizations was recorded.

Unfortunately, home blood glucose monitoring is still expensive and not regularly available in the Eastern countries and in many other areas. We must consider this painful reality when we discuss, for instance, translation of the intensified insulin therapy from a specialized University diabetes centre to general medicine departments, as Jörgens and co-workers recently suggested [3]. Even in a specialized diabetes centre the risk of severe hypoglycaemia could be high if the "intensification" of the insulin treatment lacks good and constant blood glucose monitoring [4].

Secondly, we are somewhat skeptical with regard to the handling of a more liberal diet for diabetes in general medicine

Corresponding author: Dr. C.Ionescu-Tirgoviste, Clinic of Diabetes, Nutrition and Metabolic Diseases, 5, Ion Movila Street, 79811 Bucharest II, Romania

\section{Response from the authors}

We appreciate the comments of Dr. Mincu, the Minister of Health of Romania and co-workers. We are aware that the first Eastern European Workshop on Diabetes Education, organized by the Diabetes Education Study Group (DESG) of the EASD, had taken place in Bucharest, in 1982. Lamentably though the problem of ketoacidosis prevails in Romania, as we are now being told by its Health Minister. In fact, his diabetes centre until recently the only diabetes centre in Bucharest - still runs a special intensive care unit for the treatment of ketoacidosis.

We agree that blood glucose self-monitoring is an indispensable part of treatment in patients with Type 1 diabetes, who strive for near-normoglycaemia and, at the same time, practise a liberalized diabetes diet, i.e. not following a meal plan, but rather continuously changing timing and amount of carbohydrate intake, skipping meals altogether and consuming sugar and sugar containing nutrients [1]. However, we strongly disagree that "dietary mistakes" are responsible for the development of ketoacidosis. The ingestion of even large amounts of glu-

Corresponding author: Dr. I. Mühlhauser, Abt. Stoffwechsel und Ernährung, Medizinische Klinik und Poliklinik, der Universität Düsseldorf, Moorenstrasse 4, D-40225 Düsseldorf, Germany departments. In our country - and not only! - dietary mistakes continue to be a common cause of ketoacidosis [5]. For the moment, we believe that the use of a "rigid" diet is better and safer not only in Type 2, but also in Type 1 diabetes [6].

Basically, we have no objections to the sound conclusions of Jörgens and co-workers. We simply want to emphasize that such a proposal seems to be fruitful only for a limited part of the world.

Sincerely yours,

I. Mincu, C. Ionescu-Tirgoviste, D. Cheta

\section{References}

1. Alivisatos JG, Benroubi M (1986) Education, the most important form of treatment. In: Krall LP, Alberti KGMM, Serrano-Rios M (eds) World book of diabetes in practice, vol 2. Elsevier Science Publishers, Amsterdam, pp 92-96

2. Mühlhauser I, Bruckner I, Berger M et al. (1987) Evaluation of an intensified insulin treatment and teaching programme as routine management of type 1 (insulin-dependent) diabetes. The Bucharest-Dusseldorf Study. Diabetologia 30: 681-690

3. Jörgens V, Gruber M, Bott V, Mühlhauser I, Berger M (1993) Effective and safe translation of intensified insulin therapy to general medicine departments. Diabetologia 36: 99-105

4. Tattersall RB (1986) Monitoring diabetes control. In: Krall LP, Alberti KGMM, Serrano-Rios M (eds) World book of diabetes in practice, vol 2. Elsevier Science Publishers, Amsterdam, pp 111-114

5. Dumitrescu C, Cheta D (1989) Diabetes care in Romania. Increasing interest in diabetes education. Diabetic Med 6: $739-740$

6. Ionescu-Tirgoviste C, Mincu I, Dumitrescu C et al. (1985) Education program for type II diabetic patients. Re-evaluation of some classical data on dietotherapy. Diabetes Res Clin Prac [Suppl 1]: S260 (Abstract)

cose containing nutrients, such as a bottle of Coke by adequately insulinized patients, may lead to a substantial, though transient, increase of blood glucose levels, but it will never cause ketoacidosis. Ketoacidosis is always the consequence of a lack of insulin, if patients are continuously underinsulinized, if they stop injecting insulin or if they have not been taught to appropriately increase insulin dosages during illness. These pathophysiological mechanisms have been well known since the first years of insulin treatment, and this simple knowledge has led to the almost complete elimination of ketoacidosis in many countries long before the introduction of blood glucose self-monitoring. Unfortunate$\mathrm{ly}$, in some countries and even in some diabetes centres ketoacidosis continues to be a major problem in patients with Type 1 diabetes. In the Bucharest-Düsseldorf Study [2] the incidence of ketoacidosis was exceptionally high in the control group, which received the standard treatment of the diabetes centre directed by Dr. Mincu. However, ketoacidosis was almost eradicated in patients undergoing a structured diabetes education programme. Noteably, this was the case not only in the patients, who used blood glucose self-monitoring, but also in those patients who were merely supplied with materials available in Bucharest and a so-called basic teaching programme. These patients performed urine glucose monitoring with a very cheap, though cumbersome method produced in Romania at that time. In addition, these patients could monitor acetonuria, if necessary, and they had been trained to adjust their insulin dosages themselves. 
These observations underscore that ketoacidosis can be prevented by simple and very cheap means available even in countries that face major economic problems. In this context it is of note, that our colleagues in Moscow have recently shown, that it is possible to safely improve metabolic control even if blood glucose test strips are not available and patients use only urine glucose self monitoring [3].

Adherance to a strict diet does not lead to a good quality of glycaemic control, if diabetes therapy is not based upon sufficient insulin treatment and appropriate patient education. A most impressive example for such a diet failure is the Bucharest standard treatment as evaluated in the Bucharest-Düsseldorf Study [2]. Although these patients had a very strict diabetes diet, and education was focused upon adherence to diet, an approach we have recently called "obedience training" [4], they had very high $\mathrm{HbA}_{1}$ levels (about $12.6 \%$ ), a high incidence of ketoacidosis ( 0.16 cases per patient per year), high hospitalisation rates and an excessive mortality rate. Comparably high $\mathrm{HbA}_{1}$ values have also been found in the United States, where the most rigid dietary regimens are imposed on diabetic patients using exchange lists even for vegetables, dairy products, meat, etc. [5].

Very often, money available for the care of diabetic patients can be allocated by redistribution [3]. Thus, even in countries under most stringent economic conditions, drugs which are ineffective, unnecessary or which could be easily substitued by cheaper preparations, are used in diabetic patients, such as calciumdobesilate, pentoxifylline, angiotensin converting enzymeinhibitors, lipid lowering drugs and others. It has been calculated that at a cost of DM 190 (US $\$ 118$ ) per patient per year, effective and safe insulin therapy is possible [6].

Finally, we want to draw attention to the efforts of other Romanian colleagues, both in Bucharest and other cities in the country, who have put into practise the knowledge gained from the 1982 DESG workshop in Bucharest and the Bucharest-Düsseldorf Study [2] by initiating structured treatment and teaching

\section{Increased plasma endothelin in diabetes: an atherosclerosis marker?}

Dear Sir,

Following an article in Diabetologia [1], a letter [2] - and the response from the authors [3] - regarding the role of endothelin as a marker of endothelial dysfunction in diabetes mellitus have been published. We would like to present our own experience on this subject.

We have measured plasma endothelin levels in 79 diabetic patients [23 Type 1 (age 20-50 years) and 56 Type 2 (age 5578 years)], and in 100 young ( $20-50$ years) and 36 older (5578 years) healthy control subjects.

In normotensive uncomplicated Type 1 diabetic patients $(n=13)$, the plasma endothelin levels were not significantly different from those of the age-matched control subjects. Microalbuminuria ( $>30 \mu \mathrm{g} / \mathrm{ml} ; n=10$ ) and concomitant retinopathy together with well-preserved kidney function were associated with significantly elevated endothelin levels in Type 1 diabetic patients as compared with their age-matched control subjects $(1.6 \pm 0.3$ vs $0.54 \pm 0.39 \mathrm{pg} / \mathrm{ml}, p<0.05)$.

Corresponding author: Dr. R. Patiño, Center for the Study of Hypertension, Diabetes and Obesity, Hospital Universitario San Carlos, Complutense University, E-28040 Madrid, Spain programmes for Type 1 diabetic patients. In fact, following the Declaration of San Vincente such effective treatment should be offered to all diabetic patients of Romania. The precious manpower of the nurses currently working in the intensive care unit established for the treatment of diabetic ketoacidosis could be redistributed to diabetes education, thus improving the lives of the patients and the work satisfaction of those involved in diabetes care.

Sincerely yours,

I. Mühlhauser, V. Jörgens, M. Berger

\section{References}

1. Wagener W, Overmann H, Bott U, Mühlhauser I, Berger M (1993) Do type 1 diabetic patients practise 'liberalized diet'? Diabetologia 36: A 33 (Abstract)

2. Mühlhauser I, Bruckner I, Berger M et al. (1987) Evaluation of an intensified insulin treatment and teaching programme as routine management of type 1 (insulin-dependent) diabetes. The Bucharest-Düsseldorf Study. Diabetologia 30: 681-690

3. Starostina EG, Antsiferov M, Galstyan GR et al. (1994) Effectiveness and cost-benefit analysis of intensive treatment and teaching programmes for type 1 (insulin-dependent) diabetes mellitus in Moscow - blood glucose versus urine glucose selfmonitoring. Diabetologia 37: 170-176

4. Mühlhauser I, Berger M (1993) Diabetes education and insulin therapy: when will they ever learn? J Int Med 233: 321-326

5. Klein R, Klein BEK, Moss SE, Davis MD, DeMets DL (1988) Glycosylated hemoglobin predicts the incidence and progression of diabetic retinopathy. JAMA 260: 2864-2871

6. Chantelau E (1993) Diabetes treatment in developing countries. Lancet 342: 620 (Letter)

Our results show that endothelin levels increase with age in normal subjects $(0.54 \pm 0.39 \mathrm{pg} / \mathrm{ml}$ in the young vs $1.54 \pm$ $0.9 \mathrm{pg} / \mathrm{ml}$ in the elderly, $p<0.01$ ), and as could be expected, normotensive, normoalbuminuric Type 2 diabetic patients $(n=28)$ show endothelin levels which are not statistically different from those of the control subjects. Type 2 diabetic patients with microalbuminuria $(n=10)$, in contrast to their Type 1 counterparts, also have plasma endothelin levels which are comparable to those of control subjects.

However, when macrovascular disease $(n=16)$ was considered (peripheral and coronary artery diseases) in Type 2 diabetic patients, the plasma endothelin levels were found to be significantly elevated as compared with those of 40 Type 2 diabetic patients without vascular complications $(1.56 \pm 0.6$ vs $2.3 \pm 0.9 \mathrm{pg} / \mathrm{ml}, p<0.01$ ) [4].

When retinopathy was investigated, the results continued to indicate that it is macrovascular disease which is inducing endothelin. Patients with retinopathy but without macrovascular disease ( $n=10$ of 40 , endothelin $1.43 \pm 0.4$ ) had endothelin levels which were not significantly different from those of the control group $(1.54 \pm 0.9 \mathrm{pg} / \mathrm{ml})$. Patients with retinopathy and macrovascular disease $(n=9$ of 16$)$ showed significantly elevated levels $(2.5 \pm 0.9 \mathrm{pg} / \mathrm{ml}, p<0.01)[5]$.

Diabetes is an atherogenic polygenic disease. In Type 1 diabetes there is a strong association between microalbuminuria and vascular disease [6]. This association is much less manifest in Type 2 diabetes, which itself is associated with the insulin-resistance syndrome [7] and also with the presence of other risk factors. 